\title{
Tune Up Your Teaching Toolbox!
}

The University of Tennessee Health Science Center Masters of Occupational Therapy Program

\section{INTRODUCTION}

Occupational therapy (OT) educators strive to prepare entry-level practitioners who have the expertise to meet the diverse health care needs of society.

A variety of instructional methods are used in the University of Tennessee Health Science Center (UTHSC) MOT program, including traditional lecture-based instruction (LBI), problem-based learning (PBL), team-based learning (TBL), and game-based learning (GBL).

Research suggests that active learning strategies develop the critical thinking and problem-solving skills that are necessary for effective clinical reasoning and decision-making abilities.

PBL, TBL, GBL are being successfully implemented in the UTHSC MOT Program to enhance the learning process and improve student engagement.

\section{MILLENNIAL LEARNING STYLES \& NEEDS}

Millennials (individuals who were born 1980 - 2000) are said to possess a set of unique attributes: Millennial's are skilled multi-taskers, have limited attention spans, are frequently bored, and prefer collaborative group work.

Millennials learn more effectively through hands-on rather than passive learning.

Today's OT students prefer collaboration with peers and are more reliant on feedback from others compared to past students.

Active learning approaches are consistent with the philosophy of the American Occupational Therapy Association (AOTA) on education, providing opportunities for students to integrate new knowledge and skills with that which has been previously learned.

\section{TEAM-BASED LEARNING}

Team-based learning (TBL) is a form of instruction that fosters active learning in teams of students.

TBL has proven to be feasible and effective in health professions education

Three main components:

Students complete a pre-class reading assignment

At the beginning of class, each individual student takes a quiz on the reading-a readiness assurance test (RAT).

Students then collaborate in assigned groups to complete the same RAT together.

After the individual and group RATs are complete, the groups apply the course concepts and use critical thinking skills to solve multifaceted application problems.

Research suggests that using a TBL approach fosters group collaboration, engages learners, and improves knowledge outcomes.

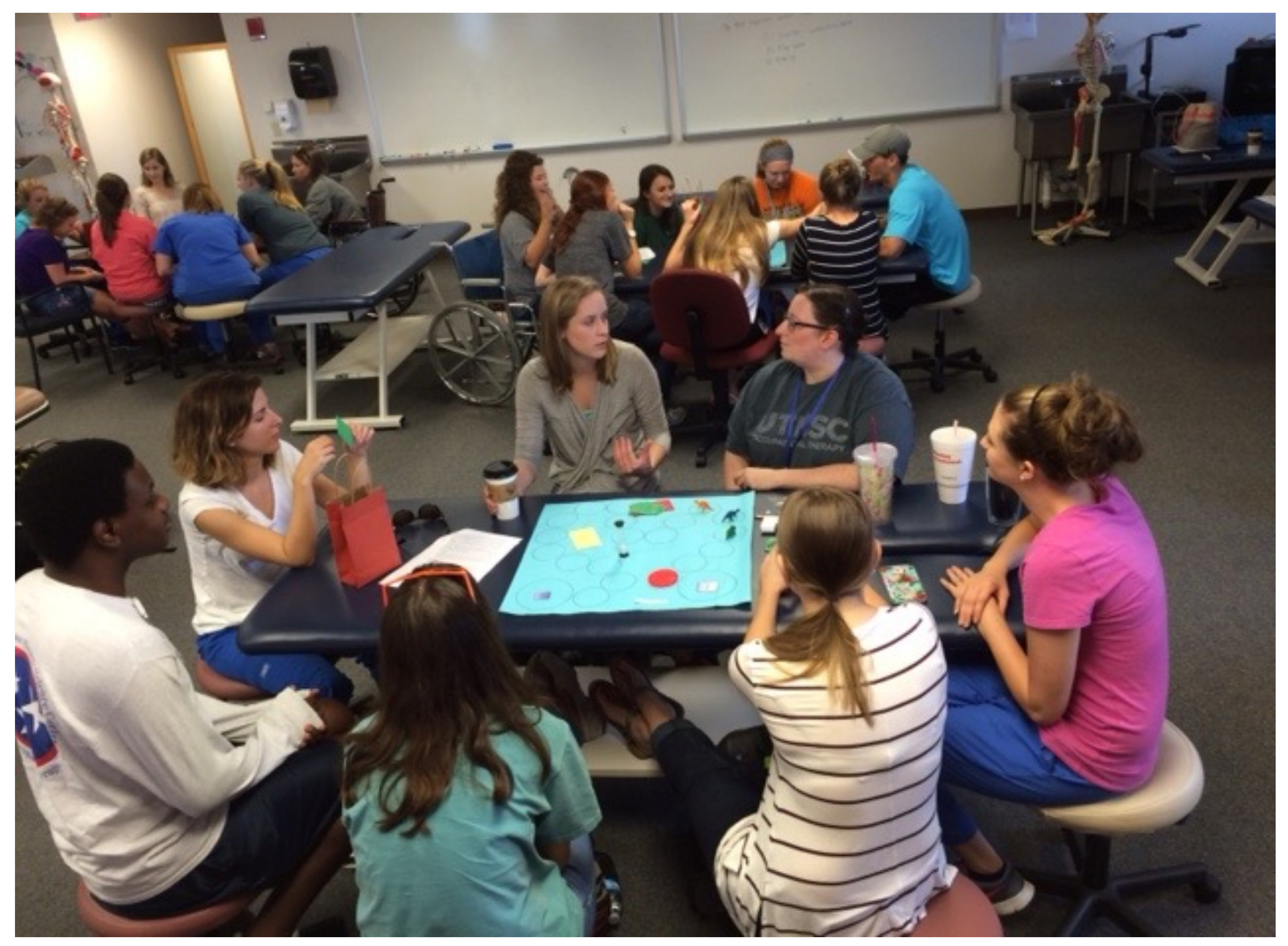

GAME-BASED LEARNING

Game-based learning (GBL) centers on the use of games to enhance the learning process.

GBL provides opportunities trial-and-error and peer modeling earning in a fun context.

- Can be carried out using commercially-sold products or independently created or adapted materials. Game formats may be digital or non-digital and may involve case-based simulations.

- GBL differs from gamification, which involves adding game elements to a nongame situation.

Games offer opportunities for rich, compelling, exciting experiences.

- There is limited research on GBL in higher education. It is similar to PBL, which provides a student-centered approach to learning, and the benefits are more likely to simulate real life

- Examples of GBL Activities:

- Brain Builder Game (pictured below) - Students understanding of neuroscience-related terms is reinforced through play involving drawing, creating with clay, singing, acting, and spelling.

- Heads Up - The Warner Brother game uses index cards or the iPad app on course-related terms.

- The Top OT Challenge - The format of the final challenge from the TV show Top Chef is modified with students using only provided materials to create a therapeutic activity for a client in a case study.

- Trivia Pursuit - Components can be changed as needed to fit the learning objectives: for example, the categories can be Equipment, Assessment, Diagnoses, etc.

- The "Just Right Challenge" Game - Each student draws a card designating an ADL or activity to be adapted based on one area labeled "Grade Up" and the other "Grade Down"

\section{PROBLEM-BASED LEARNING}

PBL uses a small group format for students to review case studies and develop treatment plans.

Increase in research in the late 1990s-early 2000, but tapered off between 2005-2010.

Resurgence of PBL research in the literature since 2010.

Improvements in critical reasoning.

Results dependent on level of facilitator knowledge and competency, well-designed case studies, and scaffolding learning outcomes.

Opportunities: inter-professional PBL groups, fieldwork

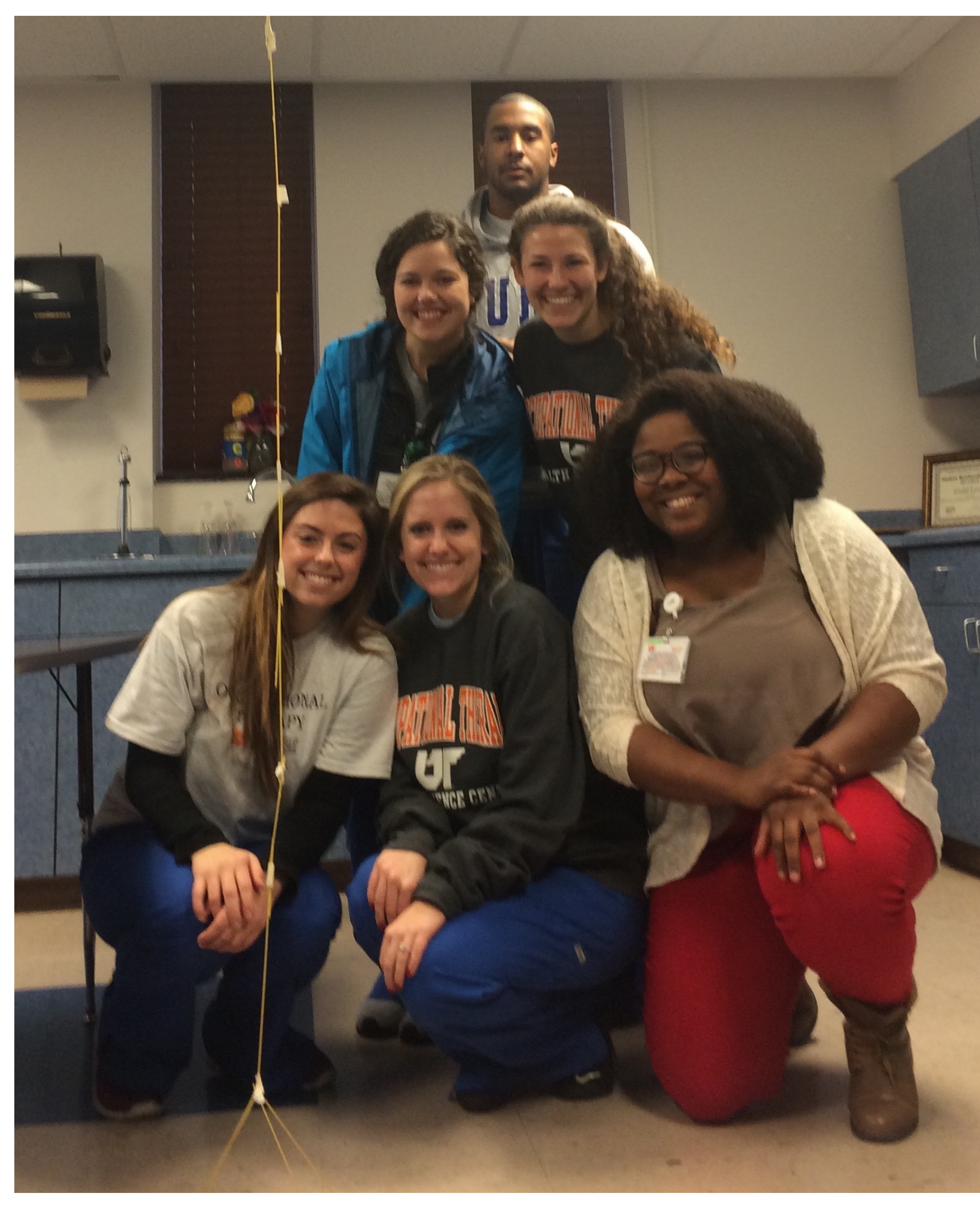

QUESTION FOR FUTURE RESEARCH

Which teaching approach best addresses critical reasoning skills in clinical situations?

Which best meets the needs of today's learners?

Is one instructional approach better suited to certain types of courses over others? If instructors use different degrees of TBL, GBL, or PBL, does this alter student's satisfaction with the particular learning method?

Would this impact learning outcomes?

REFERENCES 